\title{
Decomposing Changes in Establishment Emissions with Entry and Exit
}

J. Scott Holladay and Lawrence D. LaPlue, III

July 2020

\section{WORKING PAPER \#2020-01}

\author{
WORKING PAPER SERIES \\ DEPARTMENT OF ECONOMICS \\ HASLAM COLLEGE OF BUSINESS \\ http://econ.bus.utk.edu
}

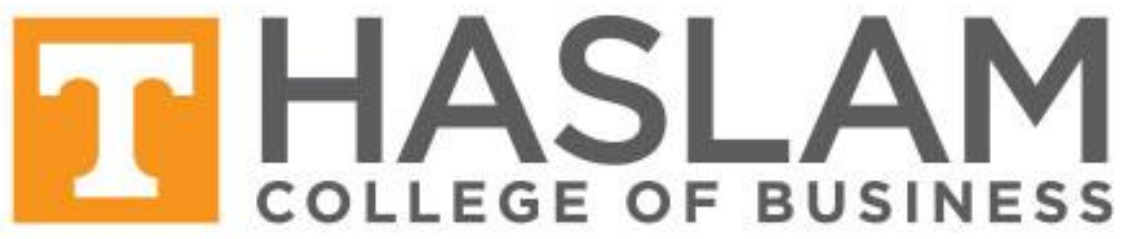

THE UNIVERSITY OF TENNESSEE, KNOXVILLE 


\title{
Decomposing Changes in Establishment Level Emissions with Entry and Exit*
}

\author{
J. Scott Holladay, ${ }^{\dagger}$ Lawrence D. LaPlue, III $^{\ddagger}$
}

July 2020

\begin{abstract}
This paper decomposes pollution releases by U.S. manufacturing establishments to show the relative importance of four establishment-level channels: entry, exit, reallocation between survivors, and within-establishment adjustment of emissions intensity. Using a panel of establishment-level output and pollution emissions to air and water for U.S. manufacturers, we decompose changes in pollution emissions into the three channels typically presented in the literature: changes in scale (output), composition (industry market share), and industry-level technique (emissions intensity). We then decompose changes due to industry-level emissions intensity into four establishmentlevel channels for three criteria air pollutants and water pollution. For volatile organic compound emissions, nearly two-thirds of the reduction in sector-level emissions intensity is due to within-establishment reductions in emissions intensity. The other third is driven by reallocation to cleaner establishments. Though the magnitudes differ, results are broadly similar for particulate matter and sulfur dioxide. Onsite releases of effluents to water exhibit a similar pattern, though the relative importance of reallocation is greater. Additionally we find that within-establishment reductions in water emissions are associated with increased transfers to offsite publicly owned treatment facilities. The heterogeneous contributions across channels suggests that the cleanup in the U.S. manufacturing sector likely has multiple sources.
\end{abstract}

JEL Classification: C10, Q50, Q56

Keywords: Emissions Decomposition, Establishment Entry and Exit, Aggregate Emissions, Emissions Intensity

${ }^{*}$ We would like to thank Georg Schaur, Kip Viscusi, Joel Rodrigue, Nouri Najjar, and participants at AERE WEAI, and the CU Environmental Workshop for helpful comments and discussions.

${ }^{\dagger}$ Department of Economics, University of Tennessee, Knoxville | jhollad3@utk.edu

${ }^{\ddagger}$ Department of Economics, New Mexico State University, Las Cruces | llaplue@nmsu.edu 


\section{Introduction}

Over the past fifty years pollution emissions from U.S. manufacturers have been declining steadily, while real output has increased. Various potential drivers of the fall in emissions have been proposed in the economics literature, with environmental regulation, international trade and changing composition of output all considered as potential candidates. A general consensus has emerged that reductions in industry emissions intensity, generally termed technique effects, have played the largest role in the cleanup. The question of why industry-level emissions intensity has been falling remains difficult to answer. The cleanup could be due to adjustment of production techniques or investment in abatement on the part of existing establishments, or to resources being reallocated, within industries, towards relatively less emissions intense establishments, or to the exit of emissions-intense incumbents and the entry of relatively clean establishments.

In this paper we first decompose changes in pollution emissions, to both air and water, for a sample of U.S. manufacturers into traditional scale, industry composition and technique effects. Copeland and Taylor (2003) develop a model that separates changes in pollution emissions into scale, composition and technique effects. ${ }^{1}$ The scale effect is the increase in pollution associated with increased economic activity and output. The composition effect is the change in pollution emissions due to shifts in economic activity towards or away from emissions-intense industries. If cleaner industries grow more quickly than dirtier industries, the composition effect will contribute to a decline in aggregate emissions per unit of output. Copeland and Taylor (2003) model the technique effect as the reduction in pollution that occurs as a polluting sector employs cleaner production techniques and lowers its aggregate emissions intensity in response to environmental regulation. ${ }^{2}$

We then extend the industry-level results by applying a method developed by Melitz and Polanec $(2015)^{3}$ to further decompose the industry-level technique effect into four establishment-level channels. The first is a direct channel capturing changes in emissions that are due to within-establishment changes in emissions intensity, which we term a "process" effect, following Cherniwchan et al. (2017). The last three capture the effects of withinindustry changes in emissions intensity due to entry and exit of polluting firms (a "selection" effect), and reallocation of output among surviving establishments (a "reallocation" effect). The resulting decomposition permits us to directly link the four establishment-level changes

\footnotetext{
${ }^{1}$ Copeland and Taylor (2003) formally models the channels introduced in Grossman and Krueger (1993) focusing on the relationship between trade and the environment.

${ }^{2}$ In practice, any reduction in an industry's emissions intensity is typically referred to as a technique effect, no matter the reason for the clean up.

${ }^{3}$ Melitz and Polanec (2015) focuses on decomposing industry productivity changes rather than emissions intensity.
} 
to aggregate emissions outcomes. Cherniwchan et al. (2017) develop a similar decomposition to discuss additional establishment-level changes that could be masked by a industry-level technique effect, include changes in output product mix within an industry, or partial offshoring of intermediate aspects of production that are more emissions intense. The decomposition approach they describe is similar to the one we employ, but they do not proceed to empirically investigate the various hypothesized channels.

Identifying the relative importance of each establishment-level channel in relation to the observed declines in industry-level emissions intensity requires information on output and pollution at the establishment level. We match pollution data from the EPA's Toxic Release Inventory (TRI) to establishment characteristics from a sample of the National Establishment Time Series (NETS). The resulting unbalanced panel consists of establishment-level observations of polluters between 1990-2001 and facilitates identification of the relative contributions of various industry and establishment-level channels to environmental cleanup over time. Though several other papers in the literature have relied on Census of Manufacturing data for establishment characteristics and the National Emissions Inventory (NEI) for estimates of air pollution emissions of chemicals regulated under the Clean Air Act, other recent papers have used a similar combination of NETS and TRI data to provide detailed analysis of the environmental effects of firm exporting (see Cui et al. (2016); Holladay (2016); Cherniwchan (2017)). We make use of an EPA-provided cross-walk to link TRI emissions to three criteria air pollutants (volatile organic compounds (VOCs), particulate matter (PM10), and sulfur dioxide $\left(\mathrm{SO}_{2}\right)$ ), which facilitates additional policy analysis, as well as comparison of our results to previous studies.

Identifying the channel responsible for the cleanup is important. Understanding whether exit of polluting establishments or reduced emissions intensity at existing establishments helps us identify potential drivers of the cleanup. ${ }^{4}$ If the cleanup is driven largely by the exit of polluting establishments, improved environmental performance might be associated with disruption in the manufacturing industry. If the cleanup is driven by within industry reallocation to the cleanest establishments that might lead to market power concerns in those industries. ${ }^{5}$ If market forces are contributing to the cleanup through multiple channels it complicates efforts to evaluate the effectiveness of environmental regulation. If firm selection, or market share reallocation are important factors associated with observed changes in emissions, then accurate analysis of the environmental effects of policy changes must take into account these general equilibrium effects.

\footnotetext{
${ }^{4}$ See Jaffe et al. (1995) for a summary of the early literature and Greenstone et al. (2012).

${ }^{5}$ Ryan (2012) demonstrates how environmental regulation can lead to competitiveness inhibiting levels of regulation for example.
} 
Our results suggest that the main driver of the substantial clean up in our sample of U.S. manufacturers has varied by pollutant. For PM10 and VOCs more than two-thirds of the cleanup has been due to the process effect, reduced emissions intensity from surviving establishments. For $\mathrm{SO}_{2}$ and hazard (toxicity weighted emissions) more than half of the observed cleanup has been achieved through the reallocation effect as output share within industries has tended to shift towards less pollution intensive establishments. Firm selection is responsible for only a very small portion of observed emissions changes, with entrants generally contributing to a small decline in industry emissions intensity, but exiting firms generally contributing to a small increase. Total water releases including transfers to public treatment works decline less than either VOCs or $\mathrm{SO}_{2}$. This is consistent with recent work by Gibson (2019),who documents a tendency of firms to substitute away from airborne emissions towards water when subjected to Clean Air Act regulations. This contrasts with work by Greenstone (2003) that finds no evidence of increases in emissions to other media in response to the Clean Air Act Amendments. Comparing results for waterborne effluents released onsite to those transferred offsite to treatment facilities reveals that establishments have been reducing their effluent releases substantially through process improvements. These on-site process improvements are associated with increased transfers to offsite treatment facilities, indicated by our estimates showing that on-site-only effluent releases have fallen much faster than total releases (including transfers to treatment facilities).

Empirical estimates of the scale, composition, and technique channels consistently find the technique effect plays the most important role in declining emissions. Levinson (2009) evaluates the impact of international trade and decomposes changes in U.S. manufacturer's emissions of four air pollutants regulated under the Clean Air Act, known as criteria pollutants, into scale, composition, and technique channels. He finds that, on average, more than three-quarters of the observed reduction in emissions can be attributed to reductions via the technique effect. ${ }^{6}$ Similar results are found by Brunel (2017) in a study of European manufacturers. Cross-country analysis of sulfur dioxide by Grether et al. (2009) identifies similar declines in $\mathrm{SO}_{2}$ emissions, indicating that the declines are not restricted to the U.S. and Europe. Levinson (2015) measures the technique effect directly, using dis-aggregated data, and finds that the technique effect accounts for as much as ninety percent of the total reduction in criteria air pollution emissions of U.S. manufacturers.

Increasing availability of firm-level data has facilitated more detailed investigation of the channels driving observed declines in industry emissions intensity. In related work, focused

\footnotetext{
${ }^{6}$ The paper acknowledges the possibility of a within-industry technique effect that could be masking up a composition effect that cannot be identified with 4-digit Standard Industrial Classification (SIC) data. We take advantage of more dis-aggregated data to examine this directly.
} 
on the carbon dioxide $\left(\mathrm{CO}_{2}\right)$ emissions of Indian firms, Martin (2011) decomposes the energy use and implied $\mathrm{CO}_{2}$ emissions of Indian manufacturers and finds that reallocation of market share to cleaner establishments and changes in energy inputs are both responsible for substantially dampening the rise in greenhouse gas emissions in India. Barrows and Ollivier (2018) and Barrows and Ollivier (2016) also make use of decomposition tools to study the $\mathrm{CO}_{2}$ emissions of Indian firms. They find evidence of substantial reallocation towards cleaner firms, but also provide evidence that changes and expansions of firm's product mixes can lead to higher firm-level emissions-intensity. Their results indicate that composition effects are similar in magnitude to industry-level technique effects. Closely related to the current paper, Najjar and Cherniwchan (2020) decompose the effects of environmental policy on the ozone and particulate matter emissions of Canadian manufacturers. They find that withinfirm responses to Canadian environmental policy, process effects, are much more important for the cleanup of ozone, while reallocation towards cleaner firms is more important for reductions in particulate matter. Further contributing to the debate regarding the importance of environmental regulation to observed declines in emissions, Shapiro and Walker (2018) provide evidence that the majority of reduction in U.S. manufacturers' criteria air pollution emissions is driven by within-product changes in per-unit emissions intensity and the observed clean up is consistent with a near doubling of the level of environmental regulation stringency between 1990 and 2008. In contrast, Cherniwchan (2017) estimates that manufacturer's responses to the U.S. entry into NAFTA accounts, on average, for nearly two-thirds of the reductions in emissions documented by Levinson (2009) and Levinson (2015). Consensus regarding the role of policy changes and their specific role in observed pollution outcomes for various pollutants remains elusive.

We contribute to this literature in two ways. First, the decomposition of pollution emissions of for our sample of U.S. manufacturing establishments isolates the share of reductions in emissions intensity associated with cleanup within existing establishments, output being reallocated from relatively dirty to relatively clean establishments, or the entry and exit of polluting firms. One important feature of the NETS data set is the identification of the exit year of the firm. This allows us to avoid the complication of defining market exit by establishment exit from the data set, which could also be due process changes and substantial cleanup thus precluding the requirement for the firm to report emissions. The results provide insights into the ways in which establishment-level activities are related to observed trends in manufacturing emissions. Second, because of detailed reporting requirements in the TRI, the data set includes matched establishment characteristics and pollution releases to both the air and water. Existing literature regarding U.S. emissions largely focuses largely on emissions of the six criteria air pollutants regulated under the Clean Air Act. We contribute 
to this literature by documenting similar declines in pollution emissions for a broad set of chemicals released to either the air or water ${ }^{7}$ and often subject to a different regulatory environment. In addition, using a cross-walk provided by the EPA, we are able decompose emissions of volatile organic compounds (VOCs), particulate matter $\left(\mathrm{PM}_{10}\right)$ and $\mathrm{SO}_{2}$, facilitating comparison of the results to other related studies.

The cleanup in the U.S. manufacturing sector has been remarkable, but it is still not well understood. There are multiple hypotheses regarding the drivers of this cleanup. More detailed understanding of the channels underlying the cleanup will help economists and policy makers as they attempt to induce further emissions reductions from U.S. manufacturing and comparable cleanups in other industries in the U.S. and abroad.

\section{Decomposing Emissions Changes}

This section briefly describes the standard decomposition performed in the literature and then lays out our additional decomposition of the aggregate technique effect into establishmentlevel channels.

\subsection{Within and Across Sector}

To understand how much of the observed decline in aggregate emissions is due to reductions in industry emissions intensity, we follow Levinson (2009) and decompose aggregate emissions into three channels: scale, composition, and industry technique. Letting $m$ denote an industry, total emissions, $Z$, in a given year, $t$, are given by:

$$
Z_{t}=\sum_{m} Z_{m t}=\sum_{m} V_{m t} E_{m t}=V_{t} \times \sum_{m} \Theta_{m t} E_{m t}
$$

where $V_{t}$ represents total annual shipments, $\Theta_{m t}=V_{m t} / V_{t}$ represents the market share held by a industry and $E_{m t}=Z_{m t} / V_{m t}$ represents the aggregate emissions intensity of the industry. The decomposition can also be expressed in vector notation for a given year: $Z=V \Theta^{\prime} E$, where $\Theta$ and $E$ are both $m \times 1$ vectors capturing industry market share and corresponding emissions intensity. Totally differentiating this equation and dividing by $Z$, percent changes in aggregate emissions can be expressed as the sum of percent changes in economic size or total output (a scale effect), changes in the relative market shares of cleaner and dirtier industries (a composition effect), and changes in industry emissions intensity (a technique

\footnotetext{
${ }^{7}$ Establishments reporting pollution releases to the TRI must document the media of release for their chemicals, whether to air, offsite incineration, direct to water, or offsite public treatment works.
} 
effect):

$$
\frac{\mathrm{d} Z}{Z}=\frac{\mathrm{d} V}{V}+\frac{\mathrm{d} \Theta}{\Theta}+\frac{\mathrm{d} E}{E}
$$

Note that if we were to only consider a single aggregate sector, $\Theta_{m t}$ would equal one in each year, and there would be no composition effect. In this case, changes in aggregate emissions over time would be driven solely by the scale and technique effects.

\subsection{Within and Across Establishment}

To understand how establishment-level adjustment can affect aggregate emissions, working through the industry technique effect, we extend the decomposition in (1). We add an additional subscript, $i$, to denote individual establishments. We represent establishmentlevel variables with lower-case letters and aggregated variables with upper-case letters.

Emissions in a given industry are the sum of the emissions from each establishment in that industry, $Z_{m t}=\sum_{i \in m} z_{i m t}$, we can further decompose the emissions intensity component from (1) as follows:

$$
E_{m t}=\sum_{i} \theta_{i m t} \cdot e_{i m t}
$$

where $\theta_{i m t}=v_{i m t} / V_{m t}$ represents an establishment's share of industry production, and $e_{i m t}=z_{i m t} / v_{i m t}$ represents an establishment's emissions intensity. Thus, $\theta_{i m t}$ captures changes in industry emissions intensity that occur as establishment market shares change as establishments enter and exit, and as resources are systematically reallocated between surviving establishments. The "process" effect represented by $e_{i m t}$ captures the environmental effect of adjustment in establishment's production processes-a within-establishment effect. $^{8}$ Written in this way, industry emissions intensity in each industry and year, $E_{m t}$, is an output-share weighted-average of each establishment's emissions intensity. Since the establishment-level analysis is inherently a sub-industry analysis, we drop the industry subscripts through the remainder of the discussion.

To understand the relative importance of reallocation, selection, and within-establishment production process adjustment in driving aggregate emissions, our empirical approach decomposes the percentage change in industry emissions intensity over time (e.g. from $t=1$ to 2): $\Delta E / E=\left(E_{2}-E_{1}\right) / \bar{E}$, where the weight $\bar{E}$ is included to express the change in scale-independent percent-change terms. ${ }^{9}$ To accomplish this additional investigation, we

\footnotetext{
${ }^{8}$ As has been noted by several related studies (see Cherniwchan et al. (2017); Barrows and Ollivier (2018)), this relatively narrow establishment-level effect could be due to multiple different adjustments, including technology upgrading, changes in input mix, changes in product mix, etc.).

${ }^{9} \bar{E}=\left(E_{1}+E_{2}\right) / 2$
} 
apply an approach suggested by Melitz and Polanec (2015) to decompose changes in aggregate emissions intensity into three channels-the changes due to survivors, entrants, and exiters-and then further decompose the surviving-establishment channel into changes due to across-establishment reallocation and within-establishment process adjustment.

Let $\Theta_{G t}=\sum_{i \in G} \theta_{i t}$ represent the aggregate market share of a group, $G$, of establishments, where the $G$ represents either survivors $(S)$, exiters $(X)$, or entrants $(N)$. Then define $E_{G t}=\sum_{i \in G}\left(\theta_{i t} / \Theta_{G t}\right) e_{i t}$ as the group's emissions intensity. Aggregate emissions intensity in periods 1 and 2 can now be expressed as a function of the aggregate output share and aggregate emissions intensity of the three groups of establishments (survivors, entrants, and exiters):

$$
\begin{aligned}
& E_{1}=\Theta_{S 1} E_{S 1}+\Theta_{X 1} E_{X 1}=E_{S 1}+\Theta_{X 1}\left(E_{X 1}-E_{S 1}\right) \\
& E_{2}=\Theta_{S 2} E_{S 2}+\Theta_{N 2} E_{N 2}=E_{S 2}+\Theta_{N 2}\left(E_{N 2}-E_{S 2}\right)
\end{aligned}
$$

where $E_{1}$ is the weighted average emission intensity, in period 1, of survivors and those which will exit and $E_{2}$ is the weighted average emissions intensity, in period 2, of those that survive into period 2 and those that are entering.

The final step of the decomposition builds on Olley and Pakes (1996) using an alternative decomposition of aggregate emissions intensity:

$$
\begin{aligned}
E_{t} & =\bar{e}_{t}+\sum_{i}\left(\theta_{i t}-\bar{\theta}_{t}\right)\left(e_{i t}-\bar{e}_{t}\right) \\
& =\bar{e}_{t}+\operatorname{cov}\left(\theta_{t}, e_{t}\right)
\end{aligned}
$$

where $\bar{e}_{t}$ is the unweighted average establishment emissions intensity, $\frac{1}{n_{t}} \sum_{i=1}^{n_{t}} e_{i t}$, and $\bar{\theta}_{t}=$ $1 / n_{t}$ is average market share. In this way, changes in aggregate emissions intensity can be expressed as the sum of the change in unweighted average emissions intensity, $\Delta \bar{e}_{i}$-this can be thought of as a within-establishment effect that is common to all establishments-and the change in the covariance (between market share and emissions intensity), $\Delta$ cov-which can be thought of as a cross-establishment reallocation effect. ${ }^{10}$ As discussed by Melitz and Polanec (2015), expressing the results in scale-independent terms when decomposing data measured in levels, as we do, will also require a scale-independent covariance measure that will also be invariant to proportional changes in emissions intensity. We follow their lead in defining such a measure as $\widetilde{\operatorname{cov}}=\operatorname{cov}(\theta, e / E)=\operatorname{cov}(\theta, e) / E$. Thus, $\widetilde{\operatorname{cov}}$ represents the

\footnotetext{
${ }^{10}$ Melitz and Polanec (2015) note that the use of the covariance operator, which would typically be multiplied by $1 / n_{t}$, is a slight abuse of notation, but, because $\theta_{n t}$ are shares, the equation essentially incorporate this division already.
} 
share of aggregate emissions intensity, $E$, driven by the correlation between market share and emissions intensity, a cross-establishment share, and the remaining share, $\bar{e} / E$, captures the share due to average establishment emissions intensity, independent of its correlation with market shares.

Combining the equations in (4) with the decomposition in (5), the change in aggregate emissions intensity is thus given by:

$$
\begin{aligned}
& \frac{\Delta E}{\bar{E}}=\frac{E_{S 2}-E_{S 1}}{\bar{E}}+\frac{\Theta_{N 2}\left(E_{N 2}-E_{S 2}\right)}{\bar{E}}+\frac{\Theta_{X 1}\left(E_{S 1}-E_{X 1}\right)}{\bar{E}} \\
& =\underbrace{\frac{\Delta \bar{e}_{S}}{\left(1-\overline{\overline{\operatorname{cov}}}_{S}\right) \bar{E}}}_{\text {Process }}+\underbrace{\frac{\Delta \operatorname{cov}_{S}}{\left(1-\overline{\overline{\operatorname{cov}}}_{S}\right)} \frac{\bar{E}_{S}}{\bar{E}}}_{\text {Reallocation }}+\underbrace{\frac{\Theta_{N 2}\left(E_{N 2}-E_{S 2}\right)}{\bar{E}}+\frac{\Theta_{X 1}\left(E_{S 1}-E_{X 1}\right)}{\bar{E}}}_{\text {Selection }}
\end{aligned}
$$

where $\bar{E}_{S}=\left(E_{S 2}+E_{S 1}\right) / 2$ and $\overline{\overline{\operatorname{cov}}}_{S}=\left(\overline{\overline{\operatorname{cov}}}_{S 2}+\overline{\overline{\operatorname{cov}}}_{S 1}\right) / 2$ represent the time average over periods 1 and 2 .

The first line decomposes the percent change in aggregate emissions intensity into the share due to survivors, entrants, and exiting establishments using (4). The second line uses (5) to further decompose the change due to survivors into the change in the distribution of emissions intensity (which can be thought of as a within-establishment adjustment in production techniques that is common to all surviving establishments) and the change due to market share reallocation between cleaner and dirtier establishments (an across-establishment reallocation of resources among survivors). This decomposition has several distinct advantages.

First, the decomposition in the second line cleanly separates changes in aggregate emissions intensity into four possible channels: within-establishment adjustment to production techniques and emissions intensity, reallocation among surviving establishments, reallocation to entrants, and reallocation away from exiting establishments (the latter two jointly capturing the environmental effects of establishment's selection in or out of the market). By building directly on the aggregate decomposition in equation (2) commonly used in related literature, our additional establishment-level decomposition results can be easily linked to changes in aggregate emissions.

Second, as noted by Melitz and Polanec (2015), this approach leverages the cross-sectional nature of the Olley and Pakes approach. Thus the decomposition of the emissions changes over time into three groups-survivors, exiting, and entering establishments-need not use the same reference emissions intensity value for each group. The decomposition is only constrained so that the sum of the three changes sum to the actual total change. Other decomposition approaches used to examine productivity, for example Foster et al. (2001), include a fixed reference group-either establishments from a single period, or an average from multiple periods-and thus tend to miss trends in productivity, which Melitz and Polanec 
(2015) argues introduces bias, tending to understate the relative contribution of survivors.

Finally, as formulated, the three channels have an intuitive interpretation. For example, the change due to survivors is the change in aggregate emissions intensity that would have occurred if there were no entry and exit. Then, using surviving establishments as a benchmark, the change due to entry, $\Theta_{N 2}\left(E_{N 2}-E_{S 2}\right)$, is the change in aggregate emissions intensity that would occur from adding or subtracting the entrants. Thus, entering establishments will contribute to a decline in aggregate emissions intensity if they have lower aggregate emissions intensity than survivors in period two: $E_{N 2}<E_{S 2}$. Conversely, exiting establishments will contribute to a decline in aggregate emissions intensity if they have a higher aggregate emissions intensity than the surviving establishments they leave behind: $E_{X 1}>E_{S 1}$.

\section{$3 \quad$ Empirical Strategy}

Our empirical analysis of the drivers of the reduction in pollution emissions from the U.S. manufacturing sector proceeds in two steps. First, we decompose the change in pollution emissions into the traditional scale, composition and industry technique effects. We then further decompose the technique effect into the four establishment-level channels described previously: changes due to reallocation among survivors, selection by entrants and exiters, and changes within establishments in their production processes. In this section we describe the data and the empirical approach we employ.

\subsection{Data}

Our approach to measuring the drivers of the fall in pollution emissions requires data on output and emissions at the establishment level. For pollution emissions we employ the EPA's Risk Screening Environmental Indicators database (RSEI) based on chemical releases reported in the Toxic Release Inventory (TRI). ${ }^{11}$ Measures of establishment output are taken from the National Establishment Time Series (NETS). In this subsection we briefly describe both data sets and the process used to link them. The merged data set is an unbalanced panel of establishment-year observations of U.S. manufacturing plants over the years 1990-2001. For each establishment we observe sales, employment, and industry, and the firm's years of operation. We are able to match these establishments to their reported TRI emissions of over

\footnotetext{
${ }^{11}$ In general, we refer to TRI emissions, which are the direct source of the emissions. The RSEI database makes use of these reported TRI emissions to evaluate potential hazards to human health based on chemical toxicity estimates.
} 
650 different chemicals. A version of this data set was employed to assess the relationship between environmental performance and export orientation in Holladay (2016).

The National Establishment Time Series (NETS) is a proprietary database compiled from Dunn and Bradstreet data on the creditworthiness of establishments. It claims to provide data on the universe of U.S. establishments. The NETS distributes the Dun and Bradstreet data to researchers and companies for market research. A number of papers in the economics literature have used the NETS. ${ }^{12}$ Most notably, Neumark et al. (2011) finds that the data in the NETS is comparable in quality to other public and private data sets, including the U.S. Census. Our dataset consists of all TRI reporters we could successfully match to NETS observations plus a ten percent sample of all remaining NETS observations in the manufacturing sector. ${ }^{13}$ Dunn and Bradstreet collect data on output, employment, location and ownership and use it to create a credit rating for establishments. The NETS includes data on the dollar value of the establishment's sales, employment, and the Dunn and Bradstreet credit rating. It also records the company's primary industry and product (8-digit SIC) and up to five other "secondary" products.

Because we focus on the contribution of establishment entry and exit to the cleanup in manufacturing, accurately measuring establishment churn is particularly important. The NETS data tracks when establishments enter and exit and provides a link to their parent firm. ${ }^{14}$ The sample contains a number of multi-establishment firms and we define entry and exit in equation (6) as firm-level outcomes. Thus, an establishment "exits" if that establishment's exit corresponds with the firm's exit. If an establishment closes, but the parent firm does not shutdown, we classify that as a component of reallocation. ${ }^{15}$ The environmental effects of any establishment closures within surviving firms is thus decomposed

\footnotetext{
${ }^{12}$ See Levine et al. (2012), Cui et al. (2016) and Cherniwchan (2017), for examples. Brinkman et al. (2015) uses a different version of the Dun and Bradstreet data on which the NETS is based.

${ }^{13}$ Haltiwanger et al. (2013) provides an extensive comparison of the NETS to official U.S. government data sets and observes that the NETS database coverage and quality is greatly improved in recent decades. However, the annual total number of firms and establishments (those with and without employees) in the NETS is generally fewer than is documented in the U.S. Census Longitudinal Database (LDB), and there is particular concern regarding the NETS coverage of startups and very small firms. More recently Barnatchez et al. (2017) conducts a detailed comparison of the NETS data with several official data sources (U.S. Census, Quarterly Census of Employment and Wages (QCEW), and County Business Patters (CBP), providing additional confirmation that differences between NETS and employer data sets (e.g. Census, QCEW, CBP, etc) are "concentrated among small establishment size classes, particularly the 1-4 employee class" (p.6). This is less of a concern for the current project given pollution reporting thresholds to the TRI (discussed further in this section).

${ }^{14}$ The NETS includes "firstyear" and "lastyear" fields identifying the first and last year that an establishment is active, respectively. The NETS links establishments to their parent firm headquarters via an "HQDuns" field. The Dunn and Bradstreet database uniquely identifies establishments and headquarters using a "DUNSnumber" and "HQDuns", respectively. All establishments in the same firm report the same "HQDuns" number.

${ }^{15}$ Results defining all entry and exit as an establishment outcome are available in the appendix.
} 
according to the second line of equation (6) as their market share goes to zero, and market share of the remaining establishments adjusts accordingly.

The TRI tracks the disposal of hundreds of different toxic chemicals regulated under the Emergency Planning and Community Right-to-Know Act. The TRI records the annual amount of toxic chemicals disposed by media of disposal, facility and chemical. Facilities are required to report their toxic emissions if they: (1) have more than ten employees, (2) "produce, process or otherwise use" more than a threshold level of any single regulated chemical, ${ }^{16}$ and (3) are in the manufacturing sector, or a handful of other related sectors. ${ }^{17}$ Due to these reporting thresholds, the TRI does not cover the universe of polluting firms, but analysis by the EPA has identified substantial overlap in the emissions reported to the TRI and the establishment-level data reported to the NEI, ${ }^{18}$ indicating that TRI airborne emissions represent the large majority of emissions reported in the NEI. The TRI has been widely used in the economics literature, ${ }^{19}$ but they are an imperfect measure of pollution emissions. Koehler and Spengler (2007) and de Marchi and Hamilton (2006) demonstrate some evidence of under-reporting in the TRI. ${ }^{20}$ TRI emissions are reported by the facilities themselves, but EPA is authorized to ensure compliance and brings a number of cases each year against polluters who misreport. ${ }^{21}$ We are not aware of any evidence that underreporting or enforcement activities changed during our sample period.

Much of the literature that assesses the fall in pollution levels in the U.S. manufacturing sector uses the National Emissions Inventory (NEI) as the source of pollution data. The NEI claims to be a comprehensive measure of point source air polluters without any of the reporting requirements that affect the TRI. Both the NEI and the TRI report emissions at the establishment level. TRI emissions are reported annually, while the NEI is generally triennial. Annual data allows us to better evaluate the impacts of entry and exit on aggregate pollution emissions. The TRI database includes establishment DUNS numbers, rather than program

\footnotetext{
${ }^{16}$ The most common threshold is 10,000 pounds but more toxic chemicals have lower thresholds ranging down to 0.1-grams for dioxin. The reporting threshold is defined by use, not emissions, so many facilities report emissions far below the threshold.

${ }^{17}$ In this paper we restrict our attention to the manufacturing sector.

${ }^{18}$ According to the EPA's report "Factors to Consider When Using Toxic Release Inventory Data" (2019), "79 percent of hazardous air pollutant releases found in the 2002 NEI data set were also documented in TRI" (p.11).

${ }^{19}$ See Andersen (2017), Gibson (2019), and Mastromonaco (2015) among many others.

${ }^{20}$ Koehler and Spengler (2007) conducts a case study in aluminum industry and finds evidence that emissions of polycyclic aromatic hydrocarbons $(\mathrm{PAH})$ are under-reported after the introduction of new regulations. de Marchi and Hamilton (2006) finds that reported reductions in TRI emissions are not always matched by reductions in pollution concentrations at air monitors and those reported emissions are not consistent with Benford's Law for lead and nitric acid.

${ }^{21}$ TRI compliance history for facilities is available from EPA's Enforcement and Compliance History Online (ECHO) database.
} 
specific facility IDs only. This facilitates more accurate and straightforward matching to establishment economic data not maintained by the EPA.

TRI reports establishment emissions by chemical. These chemicals can vary tremendously in toxicity so we aggregate them in two different ways. First, we link TRI chemical emissions to the associated criteria air pollutant (either VOCs, PM10, or $\mathrm{SO}_{2}$ ) using a cross-walk developed by the EPA (Environmental Protection Agency, 2013). This aggregation allows us to compare measures of emissions from TRI to the pollutants reported in the NEI. We also aggregate emissions using EPA provided toxicity weights that scale each pollutant by its toxicity to humans by each exposure pathway (air or water). EPA's RSEI reports these "hazard" scores as a proxy for the total toxicity of emissions from a particular source. ${ }^{22}$ The TRI reports emissions by media of release including: air, water, and offsite transfers. ${ }^{23}$ We implement our decomposition for both air and water emissions to ask whether the fall in air pollution masks shifts in pollution to water. The set of chemicals that are reported in the TRI has changed over time. We restrict our focus to the emissions of "core" TRI chemicals that have been regulated since the TRI began in 1988.

The initial matched dataset was constructed for (and described in) Holladay (2016). We begin by matching as many RSEI establishments to the NETS database as possible. The initial match was based on DUNS number, a proprietary establishment-specific identifier created by Dunn and Bradstreet. EPA treats DUNS number as optional in TRI submissions, so some polluter records do not have a DUNS. For these establishments we used a fuzzy matching procedure based on common fields in the NETS and TRI: establishment name, address, latitude-longitude and industry. We match 75 percent of TRI polluters to facilities in the NETS database. Matched plants pollute slightly more than unmatched plants, but the toxicity of emissions are not substantially different. ${ }^{24}$

While the TRI and NETS include data on non-manufacturing industries, we restrict our attention to establishments that report SIC 20-39 as their primary classification. We drop from the analysis six industries (logging and publishing sub-industries: SICs 2411, 2711, 2721, 2731, 2741 and 2771) that were fully reclassified out of manufacturing over the sample period, because they are missing price-index data across the entire sample.

We follow Levinson (2009) in dropping observations from 9 computer-related industries

\footnotetext{
${ }^{22}$ Because different chemicals have tremendous variation in their toxicity, changes in the types of chemicals released by a very small number of establishments generate substantial swings in the overall manufacturing hazard score, from year to year. In light of this, we drop the observations responsible for the top and bottom 0.0001 percent of annual-changes in recorded hazard values, similar to an approach incorporated in Cherniwchan (2017).

${ }^{23}$ These main categories are also occasionally broken down in further detail, for example airborne emissions are reported by whether they are "stack" or "fugitive" releases.

${ }^{24}$ See the appendix for further comparison and discussion of the matched dataset.
} 
whose price indices declined over the sample period. ${ }^{25}$ The NETS data contains a combination of establishment reported output, Dunn and Bradstreet imputed output and NETS imputed output. Holladay (2016) describes in detail how the output data is imputed and provides simple robustness checks for the imputed data. The final combined dataset is a panel of 1,553,970 establishment-year observations covering 1990-2001 and comprised of 200,354 establishments of which 2,699 (1.3 percent) report associated emissions. ${ }^{26}$

We refer to our dataset throughout the remainder of the paper as the analysis sample or analysis dataset. The analysis dataset is our proxy for the U.S. manufacturing sector, the ultimate population of interest. In the appendix we provide evidence that our sample is representative of U.S. manufacturing, by comparing annual output and trends in the analysis sample to data reported in the NBER Manufacturing Database. The correlation between annual 4-digit output measures in the two databases is 0.82 . We also compare entry and exit rates in the analysis sample to rates published by the U.S. Census. The entry and exit we observe in our sample is less than that reported in the Census of Manufacturers. If the analysis sample misses entry and exit by some manufacturing establishments then our estimates of the relative importance of those channels in the decomposition will be inaccurate and we will attribute the associated changes in emissions to one of the other channels, either overstating or understating their relative contribution to observed declines in emissions. We believe this is unlikely to materially affect our decomposition results for two reasons. First, manufacturing is very concentrated, with large incumbent firms accounting for the lion share of pollution emissions and output. ${ }^{27}$ Mis-measurement of entry or exit of relatively small firms is not likely to have a substantial impact on our decomposition which calculates changes by channel using market share weights. Secondly, any mis-measurement of entering or exiting establishments in the NETS sample is likely to be concentrated among very small establishments (Haltiwanger et al. (2013)). Since only plants with more than 10 employees are required to report to the TRI, the analysis sample is unlikely to miss important sources of emissions from the TRI. ${ }^{28}$

\footnotetext{
${ }^{25}$ The nine industries are: electronic computers (3571), computer storage devices (3572), computer terminals (3575), computer equipment n.e.c. (3577), calculating and accounting machines (3578), household audio and video equipment (3651), telephone and telegraph apparatus (3661), semiconductors (3674), and magnetic and optical media (3695).

${ }^{26}$ We drop all releases to off-site incinerators since these can include chemicals that were produced or released in previous years and then stored onsite before being transferred off-site.

${ }^{27}$ All major industries have been experiencing increased concentration since 1990, as documented by Autor et al. (2017), but manufacturing is particularly concentrated, with over 70-percent of sales accounted for by the 20 largest firms, on average across our sample period.

${ }^{28}$ This conclusion is further supported by comparison of emissions in the matched analysis sample to the EPA's full TRI dataset. Details of this comparison are provided in the appendix.
} 


\subsection{Decomposing the trend in pollution emissions}

TRI pollution emissions have been falling consistently since the EPA began tracking them via the TRI in 1988, while U.S. manufacturing output has risen substantially. To better understand the drivers of the improved environmental performance, we decompose changes in aggregate emissions into multiple industry and establishment channels. Figure 1 presents the decomposed results for VOC emissions reported in the TRI. Values are scaled to equal 100 in 1990.

Line (1) represents changes in deflated industry output, from 1990-2001. Line (1) identifies the scale effect, indicating that in the absence of any changes to production techniques or market share, VOC emissions in our sample would have risen 17 percent. $^{29}$

To understand the role of the composition effect, we first measure emissions intensity by SIC4 industry in 1990. ${ }^{30}$ We then calculate the change in emissions implied by changes in cross-industry output shares by multiplying the fixed 1990 emissions intensity measure by industry output in each year. This identifies the combined scale and composition effect, holding industry-level aggregate emissions intensities fixed at their 1990 levels, and is captured in line (2). If the emissions intensity of plants in our sample had remained constant over the sample period, emissions would have increased by 19 percent. The additional change in emissions due to the composition effect alone is identified by the difference between lines (1) and (2). The two percentage point increase, compared to line (1), indicates that there has been a small "brown shift" in production towards industries with a relatively high VOC emissions intensity. Line (3) captures the combined scale, composition, and process effects. Recall that the process effect is a within-establishment component of the industry-level technique effect, identified in equation (6). Adding in the process effect, emissions would have declined 43 percent from their 1990 level. Taking the difference between lines (2) and (3) reveals that within-establishment reductions in VOC emissions intensity account for a decline in emissions of 62 percentage points.

Finally, line (4) reports the change in total VOC emissions by adding in the the combined reallocation and selection effects, as output shares shift among surviving establishments and as establishments enter and exit. Cross-establishment reallocation and selection represents an additional important cleanup channel, driving down emissions by an additional 39 percentage points over the period. The sum of the process effect and the reallocation and selection effects yields the changes due to the industry-level technique effect reported in re-

\footnotetext{
${ }^{29}$ This is slightly smaller than the 21 percent increase in manufacturing output, using constant prices, reported in the NBER-CES industry database over the same period.

${ }^{30} \mathrm{We}$ measure emissions intensity by industry in 1990, as shown in equation (1), using data from our sample.
} 


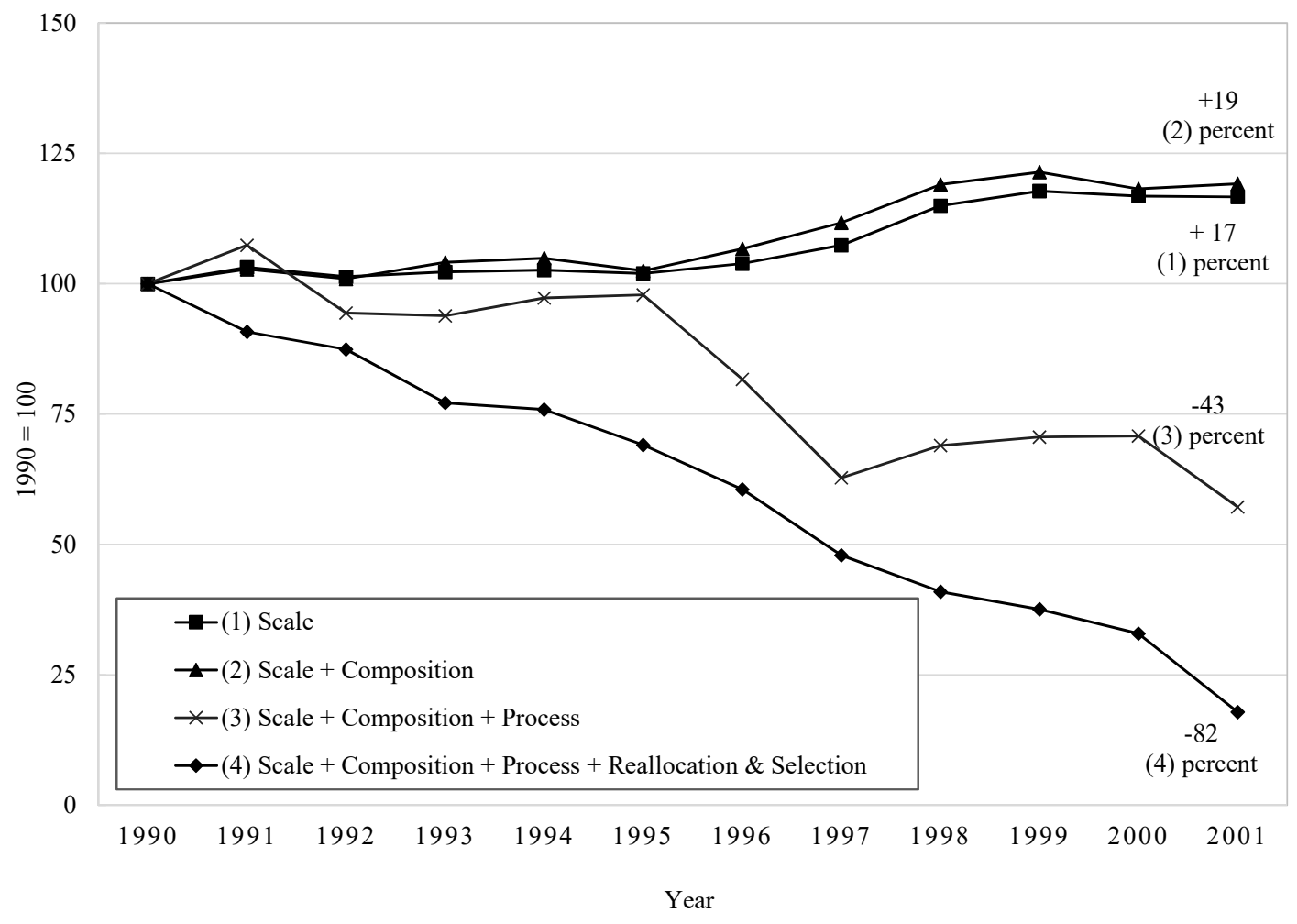

Figure 1: Volatile Organic Compounds (VOCs) Emissions from U.S. Manufacturing Notes: This figure plots the percent-change in onsite emissions of Volatile Organic Compounds (VOCs) released into the air by plants in our analysis sample, collected in the Toxic Release Inventory. The releases are decomposed into the channels identified in equations (2) and (6). The fourth line is the percent-change in reported VOC emissions relative to the base year of 1990 , and represents the sum of all of the constituent channels.

lated literature. Taken altogether the sum of the constituent channels (scale, composition, process, reallocation, and selection) yields the actual decline in emissions over the sample period. From 1990-2001, total VOC airborne emissions among manufacturing plants in our analysis sample declined by 82 percent.

We implement our decomposition across several types of emissions calculated from the TRI. We aggregate air emissions reported in the TRI into three criteria air pollutants (VOCs, PM10 and $\mathrm{SO}_{2}$ ) as well as hazard score which sums all TRI emissions weighted by toxicity. For water releases, again using the hazard score, we decompose total TRI effluent releases and TRI on-site effluent releases. Total water discharges includes toxic chemicals transported to publicly owned treatment works (POTWs) which are typically treated before release. Table 1 presents the decomposition for each of these subsets of emissions. ${ }^{31}$ Column (1) presents the scale effect, column (2) presents the combined scale and composition effects, column (3) adds in the process effect, and column (4) adds in the selection and reallocation effects.

\footnotetext{
${ }^{31}$ In this sample, 48 percent of TRI observations for airborne releases can be linked to VOC emissions, 18 percent to $\mathrm{PM}_{10}$, and 5 percent to $\mathrm{SO}_{2}$. The remaining TRI chemical releases do not link directly to a specific criteria pollutant.
} 
The sum of the process, selection, and reallocation effects is the industry-level technique effect and can be calculated from the difference between columns (4) and (2). Columns (5) and (6) report the fraction of the total cleanup attributable to within firm reductions in emissions intensity through the process effect, and the fraction due to changes in the market share and composition of firms in the industry through the reallocation and selection effects, respectively.

The scale, composition and industry technique effects for VOCs, PM10, and $\mathrm{SO}_{2}$ found in Table 1 are similar to the results presented in Shapiro and Walker (2018), estimated using National Emissions Inventory (NEI) and Census of Manufactures data, though their sample runs through 2008. The signs of the three industry-level effects are consistent across the three pollutants, and the relative magnitudes of the composition and technique effects for VOC emissions are nearly identical to those reported in Shapiro and Walker (2018). The negative composition effects estimated for PM10 and $\mathrm{SO}_{2}$ are larger in the NEI data than in our sample, suggesting that the relative contraction of point sources and industries emitting these two pollutants is larger when emissions from combustion are considered. ${ }^{32}$ Comparing the aggregate decomposition results across the two emissions databases, our results provide support for the notion that the TRI is an accurate measure of airborne emissions for these pollutants.

Table 1: Change in Aggregate Emissions by Channel: 1990-2001

\begin{tabular}{|c|c|c|c|c|c|c|}
\hline Pollutant & $\begin{array}{c}\text { Scale } \\
(1)\end{array}$ & $\begin{array}{c}\text { Scale, and } \\
\text { Composition } \\
(2)\end{array}$ & $\begin{array}{l}\text { Scale, Composition, } \\
\text { and Process } \\
(3)\end{array}$ & $\begin{array}{c}\text { Scale, Composition, } \\
\text { Process, and } \\
\text { Reallocation \& Selection } \\
(4)\end{array}$ & $\begin{array}{l}\text { Fraction of } \\
\text { cleanup due } \\
\text { to Process } \\
(5)\end{array}$ & $\begin{array}{l}\text { Fraction of } \\
\text { cleanup due } \\
\text { to Reallocation } \\
\text { \& Selection } \\
(6)\end{array}$ \\
\hline \multicolumn{7}{|l|}{ Airborne releases } \\
\hline VOC & 0.17 & 0.19 & -0.43 & -0.82 & 0.63 & 0.40 \\
\hline PM10 & 0.17 & 0.13 & -0.36 & -0.35 & 0.93 & -0.01 \\
\hline $\mathrm{SO} 2$ & 0.17 & 0.11 & -0.25 & -0.72 & 0.40 & 0.53 \\
\hline Hazard & 0.17 & 0.3 & 0.05 & -0.52 & 0.37 & 0.83 \\
\hline \multicolumn{7}{|l|}{ Water releases } \\
\hline Total (Hazard) & 0.17 & 0.09 & -0.71 & -0.54 & 1.14 & -0.25 \\
\hline On-site (Hazard) & 0.17 & 0.13 & -0.51 & -1.4 & 0.41 & 0.57 \\
\hline
\end{tabular}

Notes: This table reports the decomposition of aggregate emissions defined in equation 6 over the sample period (1990-2001). The top three rows report the decomposition for criteria pollutants estimated using EPA's crosswalk from TRI to criteria pollutants. The "Hazard" row reports the decomposition for the toxicity-weighted sum of all chemicals reported in the TRI. Column (5) is given by [(2)-(3)]/[(1)-(4)], and Column (6) is given by [(3)-(4)]/[(1)-(4)].

The "Total releases to water" row in Table 1 reports changes in total hazard associated

\footnotetext{
${ }^{32}$ Emissions from stationary combustion are reported to the NEI, but not to the TRI. In addition, the EPA estimates that stationary combustion, by manufacturing, electric utilities, and other sectors, is responsible for roughly 46 percent of $\mathrm{PM}_{10}$ pollution, and 74 percent of $\mathrm{SO}_{2}$ pollution (Environmental Protection Agency (2012)).
} 
with effluent releases by TRI reporting establishments, both onsite and transfers to publicly owned treatment works (POTWs). As shown in column (4), total releases to water have declined by about half, broadly consistent with Keiser and Shapiro (2018) findings that broad measures of water pollution (such as fishability) improved during this time frame. The relative decline in total water releases is smaller than the decline in some airborne emissions. The relatively larger decline in airborne emissions is consistent with the concern that regulation may merely induce firms to switch to an alternative release channel, an idea supported by Gibson (2019). In addition, results reveal that there has been a "green shift" towards industries releasing fewer chemical effluents, identified by the negative composition effect. ${ }^{33}$ Reallocation of output and market share towards dirtier establishments, however, has served to moderate the overall reduction in total water pollution. ${ }^{34}$

Table 1 also presents results for onsite water releases. ${ }^{35}$ Comparing the onsite releases to those including transfers to POTWs, the estimated process effect is somewhat different. In particular, when transfers to POTWs are included, within-establishment effluent intensity falls more, accounting for a decline of 80 percentage points, ${ }^{36}$ and when transfers to POTWs are omitted, within-establishment effluent intensity declines an estimated 64 percentage points via the process effect. Comparing results for the two release channels together reveals that the decline in establishments' onsite effluent intensity has been accompanied by an increase in their transfers to offsite processors. ${ }^{37}$ In addition, reallocation and selection effects are notably different when transfers to offsite POTWs are included. The estimates indicate that reallocation and selection channels have contributed to reductions on on-site releases. However, reallocation and selection effects appear to have contributed to an increase in total releases as market shares of dirtier establishments expand when transfers to POTWs are included. This difference could be due to increased use of offsite processing facilities by larger and dirtier establishments who have otherwise been slower to reduce effluents, since these releases are omitted in the on-site estimates.

To the extent that these overall trends in water releases reflect reductions in groundwater and river pollution, they suggest improved environmental quality. However, as affected POTWs are subjected to increases in waterborne pollutants, it could result in additional processing costs or new capital investment requirements, and potentially an inability to

\footnotetext{
${ }^{33}$ Column (2) minus column (1).

${ }^{34}$ Column (4) minus column (3).

${ }^{35}$ From 1990 to 2001, the aggregate effluent emissions intensity hazard score associated with on-site releases fell from roughly 9 trillion to roughly 2 trillion. Using the mid-point formula following from the use of the methods developed by Melitz and Polanec (2015), results in the decline of 1.4 given in column (4).

${ }^{36}$ Column (3) minus column (2).

${ }^{37}$ This is indicated by the much larger measured decline in effluent releases when transfers to POTWs are omitted, compared to the estimated decline when they are included.
} 
adequately treat all water received. If the increased costs associated with processing are not linked to the establishments responsible for the releases, the resulting outcome is likely to be inefficient. ${ }^{38}$

In general, the similar overall declines in water pollution and airborne emissions could be due to direct regulations contained in the Clean Air Act and Clean Water Act, ${ }^{39}$ or spillovers of technological innovation and investment, or a reallocation response of markets to other economic changes. Meaningful differences in the sign and magnitude of various underlying channels identified by these results provide additional insights that improve our understanding of the ways in which establishment decisions and activities have contributed to observed declines in pollution, and can help to inform more detailed policy analysis.

These results are generally consistent with aggregate findings in existing literature. For example, Levinson (2009) finds that between 1987-2001 the emissions of $\mathrm{SO}_{2}$ and VOCs declined, on average, by 32 percent, and the technique effect accounted for more than three quarters of the decline. Shapiro and Walker (2018) examine NEI emissions of several criteria pollutants, including VOCs, PM10, and $\mathrm{SO}_{2}$ and estimate similar scale, composition, and technique effects to those presented in Table 1. Our analysis provides the additional insight that observed reductions in emissions due to changes in industry-level techniques are generally driven by both within-establishment process changes, and also by reallocation of market activity towards cleaner firms and establishments, and that the relative importance of these channels varies, in some cases substantially, depending on the pollutant in question, and media of release.

\subsection{Decomposing the technique effect}

We decompose the industry-level technique effect, as detailed in equation (6), to examine relative importance of four underlying channels: reallocation among surviving establishments, entry and exit of establishments, and within-establishment process changes. To better understand the relative importance of each of the process, reallocation, and selection channels underlying the Figure 1 result, we present the full decomposition of the industry technique effect for VOC emissions in Table 2. The table reports annual changes in scale-independent terms and can be interpreted as percentage point changes. Column (1) reports the total change in industry emissions intensity due to changes among survivors. Columns (2) and (3) further break these changes into a within-establishment process effect and a between-

\footnotetext{
${ }^{38}$ Sewer waste regulations vary by state and municipality, as do the abilities of POTWs to obtain financing and engage in new capital projects (Rahm et al. (2018)).

${ }^{39}$ The 1972 Clean Water Act (CWA) tasked the EPA with regulating the untreated discharge of chemical emissions to rivers and lakes by municipalities, industrial customers, and other point-sources.
} 
establishment reallocation effect. Columns (4) and (5) present the selection effects of firm entry and exit. Column (6) presents the sum of columns (2), (3), (4), and (5), which corresponds to the industry-level technique effect.

Table 2: Change in Industry Airborne-Emissions Intensity by Channel

\begin{tabular}{|c|c|c|c|c|c|c|}
\hline \multirow[b]{2}{*}{ Year } & \multicolumn{3}{|c|}{$\begin{array}{l}\text { Establishments at } \\
\text { Surviving Firms }\end{array}$} & \multirow[t]{2}{*}{$\begin{array}{l}\text { Entering } \\
\text { Firms }\end{array}$} & \multirow[t]{2}{*}{$\begin{array}{l}\text { Exiting } \\
\text { Firms }\end{array}$} & \multirow[t]{2}{*}{$\begin{array}{c}\text { Total } \\
\text { (All Firms) }\end{array}$} \\
\hline & Total & Within & Between & & & \\
\hline 1991 & -18.0 & 4.2 & -22.2 & -0.6 & 6.2 & -12.4 \\
\hline 1992 & -0.3 & -11.2 & 10.8 & -0.8 & -0.5 & -1.6 \\
\hline 1993 & -10.5 & -1.5 & -9.0 & -1.0 & 0.3 & -11.2 \\
\hline 1994 & -2.3 & 3.1 & -5.4 & -0.1 & 0.7 & -1.7 \\
\hline 1995 & -6.8 & 1.3 & -8.1 & -0.6 & 1.3 & -6.1 \\
\hline 1996 & -12.6 & -18.1 & 5.5 & 0.0 & 2.2 & -10.4 \\
\hline 1997 & -18.8 & -22.4 & 3.6 & -0.6 & 3.2 & -16.2 \\
\hline 1998 & -16.0 & -1.4 & -14.6 & -0.6 & 2.0 & -14.6 \\
\hline 1999 & -7.3 & -1.2 & -6.2 & -0.6 & 1.8 & -6.2 \\
\hline 2000 & -2.7 & 1.2 & -3.9 & -0.7 & -0.3 & -3.7 \\
\hline 2001 & -15.9 & -13.5 & -2.5 & 0.3 & 0.7 & -14.9 \\
\hline
\end{tabular}

Notes: Percentage change in industry emission intensity attributable to establishments at surviving, entering and exiting firms. Emissions are total VOCs released on-site to the air. Changes in emission intensities among surviving establishments are further decomposed into changes within establishments in column (2), which we term a process effect, and reallocation among survivors in column (3). Entry and Exit are identified at the firm level. Establishments are considered to have exited if their parent firm also exits, similarly for entry.

Examining the contribution of each channel in Table 2, several trends emerge. First, the cleanup among surviving establishments, shown in column (1), is the most important factor driving observed declines in industry VOC emissions intensity. Entering and exiting firms sometimes contribute to the cleanup and sometimes increase emissions, but surviving firms reduce emissions in every year of the sample consistent with the total change in emissions across all firms. Among survivors, cleanup within establishments as well as reallocation of productive activity towards cleaner establishments are both important channels driving down emissions. However, both channels do not contribute to reductions in every year. For example, in 1992 reallocation of market share toward dirtier establishments was a drag on the cleanup among survivors that would otherwise have occurred if driven solely by the within-establishment process effect. In the last four years of the panel both within-firm process changes and between-firm reallocation contribute consistently to the clean up. 
Second, though not representing a large share of emissions activity, ${ }^{40}$ entering firms are typically cleaner than the average existing establishment, indicated by the negative effect their entry has on industry emissions intensity in each year (except 2001). Finally, exiting firms are also usually cleaner than the surviving establishments they leave behind, on average, as is indicated by the positive signs in column (5) in most years. Recall from equation (3) that exiting establishments will contribute to a decline in aggregate emissions intensity if exiting establishments have a higher emissions intensity than the establishments they leave behind. The positive values in the exiting establishments column raise aggregate emissions intensity, thus indicating that exiting establishments, on average, have a lower emissions intensity than incumbents they leave behind in those years. Overall, the the environmental effects of firm selection are generally smaller than the effects due to changes among surviving firms. Our results demonstrate that, while important, entry and exit exhibit a smaller relative effect on emissions outcomes.

Table 3: Change in Industry Emissions Intensity - All Pollutants

\begin{tabular}{|c|c|c|c|c|c|c|}
\hline \multirow[b]{2}{*}{ Pollutant } & \multicolumn{3}{|c|}{$\begin{array}{l}\text { Establishments at } \\
\text { Surviving Firms }\end{array}$} & \multirow{2}{*}{$\begin{array}{c}\text { Entering } \\
\text { Firms } \\
\\
(4)\end{array}$} & \multirow{2}{*}{$\begin{array}{c}\begin{array}{c}\text { Exiting } \\
\text { Firms }\end{array} \\
(5)\end{array}$} & \multirow{2}{*}{$\begin{array}{c}\text { Total } \\
\text { (All Firms) } \\
(6)\end{array}$} \\
\hline & $\begin{array}{l}\text { Total } \\
(1)\end{array}$ & $\begin{array}{l}\text { Within } \\
(2)\end{array}$ & $\begin{array}{l}\text { Between } \\
\quad(3)\end{array}$ & & & \\
\hline \multicolumn{7}{|l|}{ Airborne releases } \\
\hline VOC & -111.3 & -59.4 & -51.9 & -5.2 & 17.7 & -98.8 \\
\hline PM10 & -94.0 & -52.2 & -41.8 & -5.0 & 47.1 & -51.9 \\
\hline $\mathrm{SO} 2$ & -59.4 & -41.9 & -17.5 & -4.8 & -24.5 & -88.7 \\
\hline Hazard & -52.7 & -12.0 & -40.7 & -5.9 & -3.2 & -61.8 \\
\hline \multicolumn{7}{|l|}{ Water releases } \\
\hline Total (Hazard) & -43.9 & -87.4 & 43.6 & -7.6 & -18.7 & -70.2 \\
\hline On-site (Hazard) & -117.7 & -67.9 & -49.7 & 8.0 & -46.7 & -156.4 \\
\hline
\end{tabular}

Notes: Each row decomposes the industry technique effect across the full sample period for different pollutants. Units are percentages of 1990 emissions for that pollutant. Column (1) reports the total change in emissions intensity at plants that survive in each period. Columns (2) and (3) decompose that change in emissions intensity into within plant changes and changes in output respectively. Columns (4) and (5) report changes in emissions intensity due to entering and exiting firms. Column (6) reports the total change in emissions intensity across the all firms for the entire sample period.

Finally we report the decomposition of the technique effect for all pollutants aggregated across the entire sample period in Table 3. The columns are the same as in Table 2, but each

\footnotetext{
${ }^{40}$ Recall from equation (6) that emissions measures for surviving, entering, and exiting firms are weighted by the market share of each group. Relatively small market share of entrants means that differences in their emission intensity have smaller effects on aggregate outcomes. See appendix for further discussion of the market shares of entrants and exiters.
} 
row represents a single pollutant. ${ }^{41}$ The results again illustrate the variation in the sources of the cleanup across pollutant types. For the air pollutants, within surviving establishment reductions in emissions intensity (the process effect) contribute between 23 and 71 percent of the total clean up due surviving establishments, but for water effluents they account for more than one-hundred percent of on-site reductions. Entering establishments contribute to the cleanup for all pollutants except on-site water effluent. Exiting firms are actually cleaner than average survivors in terms of VOC and PM10 emissions, but dirtier for $\mathrm{SO}_{2}$, airborne hazard, and both measures of water pollution. The heterogeneous contributions across channels suggests that the broad based cleanup across manufacturing plants in our analysis sample likely has multiple sources. It is difficult to suggest a single policy change or market force that would lead to a cleanup through different channels for different pollutants.

\section{Conclusion}

The rapid decrease in pollution emissions from U.S. manufacturers has been the subject of a great deal of attention. The existing economics literature has found that the majority of industry pollution emissions reductions have come from reduction in emissions per unit of output, rather than changes in the quantity or categories of goods produced. In this paper, we employ a data set that matches establishment characteristics and pollution emissions to corroborate and extend this work. We provide evidence that the fall in criteria air pollution is mirrored by a fall in toxicity weighted emissions and water pollution. The primary driver of the aggregate decline in toxic pollution emissions is reduced emissions intensity within industries. Using a cross-walk developed by the EPA, we are able to link our estimates of scale, composition and industry technique effects to three criteria air pollutants: VOCs, $\mathrm{SO}_{2}$, and PM10. The criteria-air pollutant estimates for these three aggregate effects are similar to those found in related studies using triennial NEI data. Leveraging the data-set's identification of establishment and parent-firm entry and exit and establishment production measures, we are able to decompose the decline in within-industry emissions intensity into four channels: reallocation among surviving establishments, selection by entering and exiting establishments, and a within-establishment process effect.

Our results show that the industry composition effect is generally responsible for only a relatively small portion of observed changes, and its effects vary depending on the pollutant in question. As with previous studies, nearly all of the documented environmental improvements across all air and water emissions we decompose are due to reductions in

\footnotetext{
${ }^{41}$ The total decline in industry emissions intensity for VOCs (-99) differs slightly from the implied decline in Figure 1 (-101), seen by subtracting line (2) from line (4), due to rounding.
} 
the pollution intensity of a sample of U.S. manufacturers. Underlying this technique effect, roughly two-thirds the reduction in VOC pollution emissions from plants in our sample comes from reduced emissions intensity at surviving establishments. The remaining portion is driven by reallocation of output from relatively dirty to cleaner establishments in the same industry. In most years, the selection of firms in and out of our sample is responsible for a very small increase in emissions. These general results are generally similar for the other criteria pollutants and toxicity weighted emissions though with variation in the magnitudes.

Our analysis of effluent releases to water indicates that as with airborne emissions, total hazardous releases to water have fallen (both for on-site only releases, and when transfers to treatment facilities (POTWs) are incorporated), and more pollution is being transported to POTWs. Our decomposition results indicate that for both groupings, within establishment process effects are very important. However, reallocation and selection effects are of greater importance than process improvements when evaluating on-site water pollution and, when transfers to POTWs are considered, reallocation has actually been toward dirtier establishments, thus serving to moderate the reduction in total water releases.

The differences in the contribution of the various channels across disposal media provide suggestive evidence that direct regulation of air and water pollution may have played a broad role, but it is possible that the cleanup was influenced indirectly by other environmental policies, increased competition (either domestic or foreign), or other channels either alone or in conjunction with environmental regulations.

Our result unpacks the primary channels underlying the fall in pollution emissions, but does not explain why there has been a remarkable improvement in within establishment environmental performance or a general reallocation of market activity towards less airpollution intensive establishments. Across pollutants the cleanup of existing firms has played a major role in reducing emissions intensity. The cleanup is not being driven by the exit of the dirtiest plants, the average exiting plant is cleaner than survivors. These results have implications for our understanding of the impact of environmental regulation on polluters and the design of environmental policy. 


\section{References}

Agency, E. P. (2013). 2008 National Emissions Inventory. Technical Support Document version 3. Technical Report September.

Andersen, D. C. (2017). Do credit constraints favor dirty production? Theory and plant-level evidence. Journal of Environmental Economics and Management, 84:189-208.

Autor, B. D., Dorn, D., Katz, L. F., Patterson, C., and Reenen, J. V. (2017). Concentrating on the Fall of the Labor Share. American Economic Review: Papers and Proceedings, 107(5):180-185.

Barnatchez, K., Crane, L. D., and Decker, R. (2017). An assessment of the national establishment time series (nets) database. FEDS Working Paper No. 2017-110.

Barrows, G. and Ollivier, H. (2016). Emission intensity and firm dynamics: reallocation, product mix, and technology in India. Grantham Res. Inst. Clim. Change Environ., London Sch. Econ. Polit. Sci., London (Working Paper, No. 275).

Barrows, G. and Ollivier, H. (2018). Cleaner firms or cleaner products? How product mix shapes emission intensity from manufacturing. Journal of Environmental Economics and Management, 88:134-158.

Becker, R. A., Gray, W. B., and Marvakov, J. (2013). NBER-CES Manufacturing Industry Database: Technical Notes.

Brinkman, J., Coen-Pirani, D., and Sieg, H. (2015). Firm Dynamics in an Urban Economy. International Economic Review, 56(4):1135-1164.

Brunel, C. (2017). Pollution Offshoring and Emission Reductions in EU and US Manufacturing. Environmental and Resource Economics, 68(3):621-641.

Cherniwchan, J. (2017). Trade Liberalization and the Environment: Evidence from NAFTA and U.S. Manufacturing. Journal of International Economics, 105:130-149.

Cherniwchan, J., Copeland, B. R., and Taylor, M. S. (2017). Trade and the Environment: New Methods, Measurements, and Results. Annual Review of Economics, 9(2):59-85.

Copeland, B. R. and Taylor, M. S. (2003). Trade and the Environment: Theory and Evidence. Princeton University Press, Princeton, NJ. 
Cui, J., Lapan, H., and Moschini, G. (2016). Productivity, Export, and Environmental Performance: Air Pollutants in the United States. American Journal of Agricultural Economics, 98:447-467.

de Marchi, S. and Hamilton, J. T. (2006). Assessing the Accuracy of Self-Reported Data: an Evaluation of the Toxics Release Inventory. Journal of Risk and Uncertainty, 32(1):57-76.

Environmental Protection Agency (2012). Our Nation's Air: Status and Trends Through 2010. Technical report, Research Triangle Park, NC.

Foster, L., Haltiwanger, J. C., and Krizan, C. J. (2001). Aggregate Productivity Growth: Lessons from Microeconomic Evidence. In Charles R. Hulten, Dean, E. R., and Harper, M. J., editors, New Developments in Productivity Analysis, number January, chapter 8, pages 303-372. University of Chicago Press, Chicago, IL.

Gibson, M. (2019). Regulation-induced pollution substitution. The Review of Economics and Statistics, 101(5):827-840.

Greenstone, M. (2003). Estimating Regulation-Induced Substitution: The Effect of the Clean Air Act on Water and Ground Pollution . American Economic Review, 93(2):442-448.

Greenstone, M., Syverson, C., and List, J. A. (2012). The Effects of Environmental Regulation on the Competitiveness of U.S. Manufacturing. NBER Working Paper, (18392).

Grether, J. M., Mathys, N. A., and De Melo, J. (2009). Scale, technique and composition effects in manufacturing SO2emissions. Environmental and Resource Economics, 43(2):257-274.

Grossman, G. M. and Krueger, A. B. (1993). Environmental Impacts of a North American Free Trade Agreement. In Garber, P., editor, U.S. Mexico Free Trade Agreement, pages 13-56. MIT Press, 2nd edition.

Haltiwanger, J. C., Jarmin, R. S., and Miranda, J. (2013). Who Creates Jobs? Small Versus Large Versus Young. The Review of Economics and Statistics, 95(2):347-361.

Holladay, J. S. (2016). Exporters and the Environment. Canadian Journal of Economics, 49(1):147-172.

Jaffe, A. B., Peterson, S. R., Portney, P. R., and Stavins, R. N. (1995). Environmental regulation and the competitiveness of US manufacturing: what does the evidence tell us? Journal of Economic Literature, 33(1):132-163. 
Keiser, D. A. and Shapiro, J. S. (2018). Consequences of the clean water act and the demand for water quality. The Quarterly Journal of Economics, 134(1):349-396.

Koehler, D. A. and Spengler, J. D. (2007). The toxic release inventory: fact or fiction? A case study of the primary aluminum industry. Journal of Environmental Management, $85(2): 296-307$.

Levine, D. I., Toffel, M. W., and Johnson, M. S. (2012). Randomized Government Safety Inspections Reduce Worker Injuries with No Detectable Job Loss. Science, 336(April):344347.

Levinson, A. (2009). Technology, International Trade, and Pollution from US Manufacturing. American Economic Review, 99(5):2177-2192.

Levinson, A. (2015). A Direct Estimate of the Technique Effect: Changes in the Pollution Intensity of US Manufacturing, 1990 - 2008. Journal of the Association of Environmental and Resource Economists, 2(1):43-56.

Martin, L. A. (2011). Energy efficiency gains from trade: greenhouse gas emissions and India's manufacturing sector. mimeo.

Mastromonaco, R. (2015). Do environmental right-to-know laws affect markets? Capitalization of information in the toxic release inventory. Journal of Environmental Economics and Management, $71(\mathrm{C}): 54-70$.

Melitz, M. J. and Polanec, S. (2015). Dynamic Olley-Pakes Decomposition with Entry and Exit. RAND, 46(2):362-375.

Najjar, N. and Cherniwchan, J. (2020). Environmental Regulations and the Clean-Up of Manufacturing: Plant-Level Evidence From Canada. Review of Economics and Statistics, Advance Publication:1-45.

Neumark, D., Wall, B., and Zhang, J. (2011). Do Small Businesses Create More Jobs? New Evidence for the United States from the National Establishment Time Series. Review of Economics and Statistics, 93(1):16-29.

Olley, S. and Pakes, A. (1996). The Dynamics of Productivity in the Telecommunications Equipment Industry. Econometrica, 64(6):1263-1297.

Rahm, B. G., Morse, N., Bowen, M., Choi, J., Mehta, D., and Vedachalam, S. (2018). Is bigger better? Driving factors of POTW performance in New York. Water Research, 135:134-143. 
Ryan, S. P. (2012). The Costs of Environmental Regulation in a Concentrated Industry. Econometrica, 80(3):1019-1061.

Shapiro, J. S. and Walker, R. (2018). Why is pollution from us manufacturing declining? the roles of environmental regulation, productivity, and trade. American Economic Review, 108(12):3814-54. 


\section{Appendix}

\section{Comparing the analysis sample to other data sources}

In this section we provide evidence that the analysis sample used in this paper is representative of output and emissions of the U.S. manufacturing sector. The first comparison indicates that the NETS extract used in the analysis dataset correlates well with output data from the NBER. Next, we compare entry and exit rates in the analysis dataset to the Census of Manufacturers. Finally, we compare the emissions characteristics of the matched polluting establishments in the analysis sample to the full TRI database, and discuss EPA analysis comparing overlap between emissions reported to the TRI and the National Emissions Inventory (NEI).

We start by comparing output measures from the NETS data to data reported in the NBER-CES Manufacturing Industry Database (Becker et al. (2013), each measured in billions of dollars. Using 4-digit prices indices from the NBER to maintain constant prices, Figure 2 shows the trends in NETS sales value (right axis) and the shipment value from the NBER database (left axis). Recall that the analysis dataset uses a roughly 10-percent extract of manufacturing establishments from the NETS, so the NBER and analysis sample output levels are different. The trends are remarkably similar. In addition, correlation between 4-digit industry output (with constant prices) in the NBER and analysis sample is 0.82 (correlation of the nominal annual sales values is even higher, at 0.94). These comparisons provide further evidence that changes in the output of plants in the analysis dataset used in the main decomposition are a good proxy for changes in overall manufacturing output. 


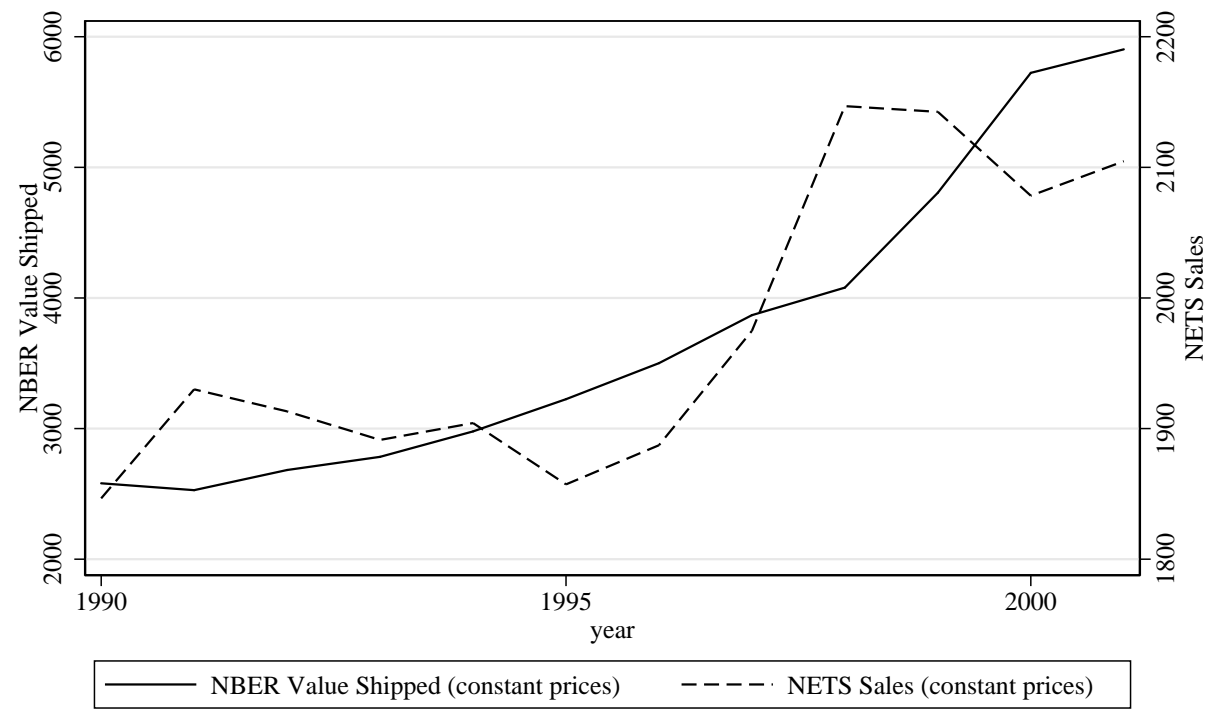

Figure 2: Comparing NETS and NBER output

Table 4 compares entry and exit rates of firms in the matched TRI-NETS analysis sample to the Census of Manufactures. We observe lower rates of entry and exit in the NETS than is reported in the Census data. Haltiwanger et al. (2013) makes a similar observation for a larger extract from the NETS, and suggests that this may be due to the NETS database having less coverage of very small establishments, particularly those with one or zero employees.

Although our focus is the role of entry and exit on emissions outcomes, the fact that entry and exit in our sample may not exactly match the broader economy is unlikely to materially effect our decomposition for two reasons. First, comparing sales of polluters to sales of all establishments in our sample, results in Table 5 indicate that establishments that report emissions tend to be larger. ${ }^{42}$ While the matched observations appear to over-sample large establishments relative to the broader economy, these establishments are more likely to meet the reporting thresholds established by the TRI. Reported emissions are likely to cover the majority of actual U.S. toxic pollution emissions even if small polluters are exempt. Second, the distribution of emissions in the matched TRI-NETS analysis sample is consistent with the pollution measures in the complete TRI data set (see Figure 4 below and related discussion), lending further confidence that the results we report are representative of the channels driving aggregate emissions for all TRI reporters.

Table 5 reports the sample statistics for sales (and log sales) for the the sub-sample of polluting establishments and for the entire analysis sample. Just over five percent of NETS

\footnotetext{
${ }^{42}$ Relatively large establishments tend to enter and exit at lower rates than their smaller counterparts, but without access to the establishment level Census of Manufacturers data we cannot confirm whether the entry and exit rates in the NETS are consistent with broader measures for large manufacturing establishments.
} 
Table 4: Market Share, Entry and Exit Rates by Firms (NETS)

\begin{tabular}{|c|c|c|c|c|c|c|}
\hline \multirow[b]{3}{*}{ Year } & \multirow{2}{*}{\multicolumn{2}{|c|}{$\begin{array}{c}\text { Market Share } \\
\text { NETS }\end{array}$}} & \multicolumn{4}{|c|}{ Entry and Exit Rates } \\
\hline & & & \multicolumn{2}{|c|}{ NETS } & \multicolumn{2}{|c|}{ U.S. Census } \\
\hline & Entrants & Exiters & Entry & Exit & Entry & Exit \\
\hline 1991 & 0.2 & 14.3 & 0.7 & 10.8 & 7.8 & 7.8 \\
\hline 1992 & 0.3 & 5.1 & 0.8 & 5.6 & 7.1 & 8.1 \\
\hline 1993 & 0.4 & 4.5 & 2.3 & 5.5 & 8.3 & 7.6 \\
\hline 1994 & 0.6 & 1.4 & 1.3 & 3.1 & 8 & 7.6 \\
\hline 1995 & 0.2 & 5 & 1.4 & 6.7 & 8.2 & 7.4 \\
\hline 1996 & 0.3 & 3.9 & 1.5 & 7 & 7.8 & 7.5 \\
\hline 1997 & 0.4 & 2.5 & 1.6 & 4.4 & 7.4 & 7.5 \\
\hline 1998 & 0.4 & 3.6 & 1.2 & 5.2 & 7.1 & 7.5 \\
\hline 1999 & 0.4 & 1.7 & 1.4 & 2.6 & 6.2 & 7.6 \\
\hline Mean & 0.4 & 4.7 & 1.4 & 5.7 & 7.5 & 7.6 \\
\hline
\end{tabular}

Entrants and Exiters are identified by a firstyear and lastyear indicator (respectively) in the NETS database and their HQDuns number. Market Share is the ratio of total output by establishments in each group (Entrants or Exiters) to total output in each year. Entry Rates are the ratio of the number of entering firms to the total number of firms. Exit Rates are the ratio of the number of exiting firms to the total number of firms in the previous year.

establishment observations are matched to TRI reporters. The full analysis sample contains a large number of establishments that do not report emissions because they do not pollute or do not meet the reporting requirements. Because establishments with fewer than 10 employees are not required to report to the TRI we expect to see fewer small establishments in the matched sample and that is consistent with the statistics reported in Table 5.

Figure 3 compares sales statistics of all firms in the analysis dataset to the subset of polluters. The top panel presents the distribution for polluters and the bottom panel presents the full analysis sample. The shape of the distributions is quite similar, but, consistent with the summary statistics reported above, the sales distribution for polluting establishments only is shifted roughly three log points to the right.

As reported in Holladay (2016), the matched data set contains around two-thirds of the full set of TRI reporting manufacturers. Figure 4 presents the distribution of log pounds of toxic emissions for the analysis dataset (top panel) and the EPA's full TRI data set (bottom panel), for the years 1990-2001. The distributions are very similar. The sample mean, standard deviation and median are within rounding error of each other. This gives us confidence that the matched sample is a good representation of the full TRI data set. 

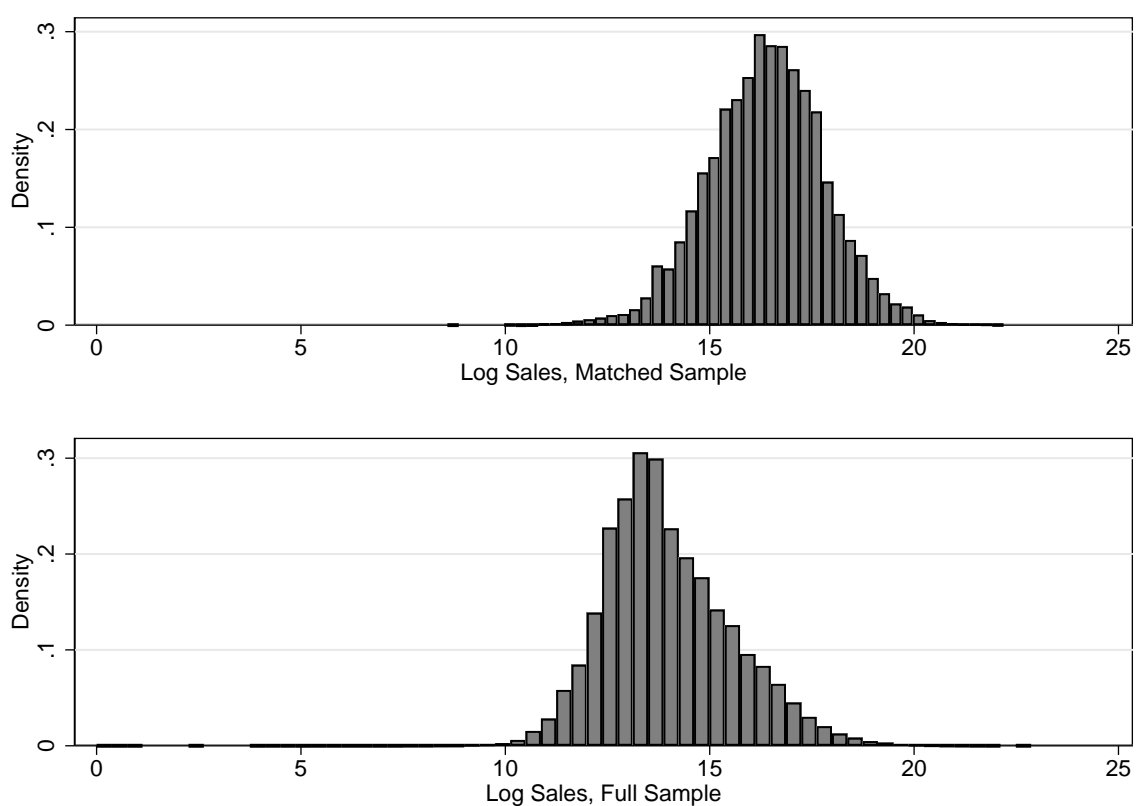

Figure 3: Sample Comparison: NETS (Sales)

Note: The top panel shows the distribution of establishment log-sales of polluting establishments from the NETS database that also report emissions to the TRI. The lower panel shows the distribution of log-sales for the larger analysis sample, including establishments that do not report emissions to the TRI. Both distributions are restricted to manufacturing (SIC2 20-39) establishments operating from 1990 - 2001. The establishment sales data prices are held constant using sector-specific NBER-CES price indices.
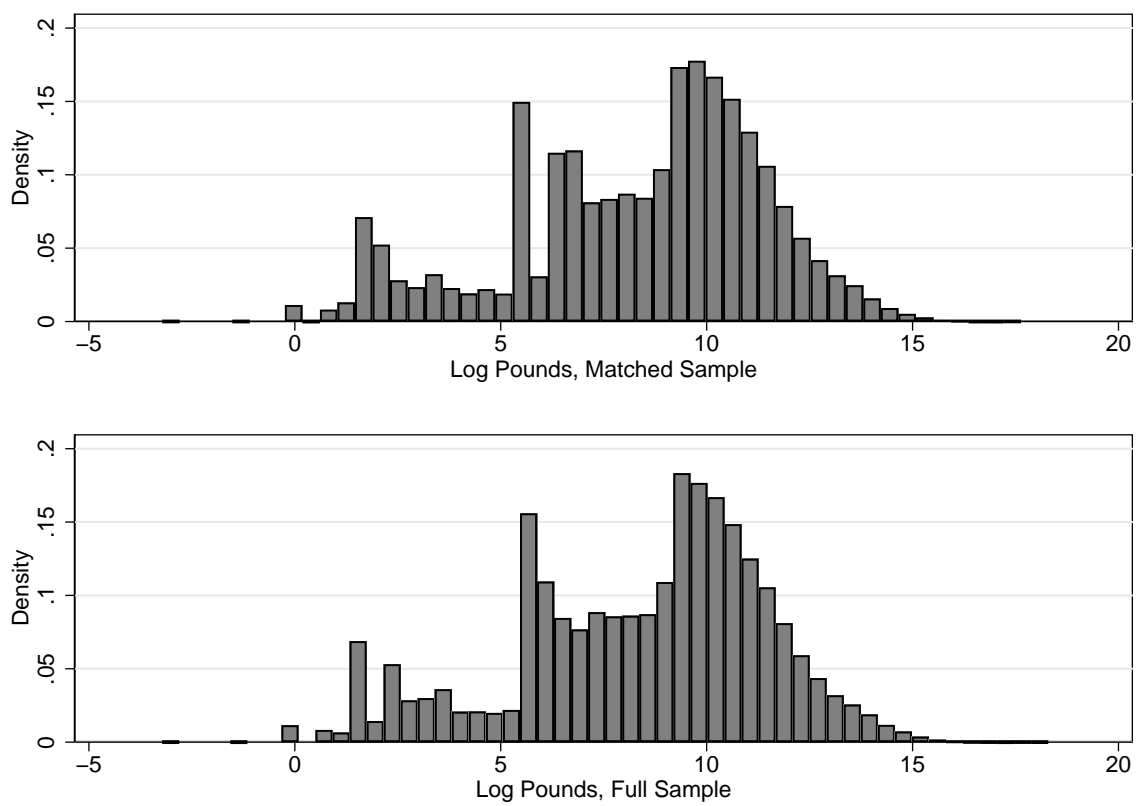

Figure 4: Sample Comparison: TRI (Pounds)

Note: The log-emissions data for the top panel of this figure are taken from matched TRI-NETS establishment-level analysis data set described in the text. The distribution in the lower panel is based on the log-pounds of manufacturing establishments (SIC2 20-39) from the full RSEI database. 
Table 5: Sample Comparison: NETS (Sales)

\begin{tabular}{lccccc}
\hline & \multicolumn{2}{c}{ Sales } & & \multicolumn{2}{c}{ Log Sales } \\
\cline { 2 - 3 } \cline { 5 - 6 } & Polluters & Full NETS & & Polluters & Full NETS \\
\hline Mean & $37,000,000$ & $7,603,683$ & & 16.4 & 14.1 \\
Std. Dev. & $105,000,000$ & $47,300,000$ & & 1.4 & 1.6 \\
Median & $13,500,000$ & $1,055,600$ & & 16.4 & 13.9 \\
Min & 5,336 & 1 & & 8.6 & 0 \\
Max & $4,330,000,000$ & $8,490,000,000$ & & 22.2 & 22.9 \\
& & & & & \\
Obs. & 91,787 & $1,295,027$ & & 91,787 & $1,295,027$ \\
\hline \hline
\end{tabular}

The first two columns compare the sample Sales statistics for polluting establishments, matched from the RSEI to the NETS database, to the larger 10percent NETS sample including both polluters and non-polluters. The second two columns compare the sample Log-Sales statistics.

EPA has published a comparison and analysis of establishments and emissions reported in both the TRI and National Emissions Inventory (NEI). The EPA analysis indicates that while a larger number of stationary sources report emissions to the NEI than the TRI, the TRI captures 79 percent of the hazardous emissions reported in the NEI, ${ }^{43}$ thus providing evidence that the decomposition analysis is broadly identifying the major drivers of documented emissions declines.

\section{Defining entry and exit}

As noted in the main text, the definition of entry and exit has important implications for the estimation of the impacts of entry, exit and reallocation. In this section we briefly present decomposition results when we define entry and exit as occurring at the establishment level, without regard to the status of the parent firm. Table 6 reports the reallocation and within establishment technique effects for VOCs using the establishment level definitions of entry and exit. These results indicate that, on net, plants in our sample are reallocating production towards dirtier establishments, and that an even larger share of the observed cleanup in toxic pollution emissions is due to the within establishment cleanup, the technique effect. The finding of a positive reallocation effect is reversed using our preferred approach which defines entry and exit as occurring at the firm level, suggesting that a substantial amount of the establishment closures are a within-firm phenomena.

Using an establishment-only definition of entry and exit, selection within industries tends

\footnotetext{
${ }^{43}$ EPA report "Factors to Consider When Using Toxic Release Inventory Data" (2019).
} 
Table 6: Change in Aggregate Emissions Intensity by Channel

\begin{tabular}{|c|c|c|c|c|c|c|}
\hline \multirow[b]{2}{*}{ Year } & \multicolumn{3}{|c|}{ Surviving Establishments } & \multirow{2}{*}{$\begin{array}{c}\text { Entering } \\
\text { Establishments } \\
\\
(4)\end{array}$} & \multirow{2}{*}{$\begin{array}{c}\text { Exiting } \\
\text { Establishments } \\
(5)\end{array}$} & \multirow{2}{*}{$\begin{array}{c}\text { Total } \\
\text { (All Establishments) } \\
(6)\end{array}$} \\
\hline & $\begin{array}{c}\text { Total } \\
(1)\end{array}$ & $\begin{array}{l}\text { Within } \\
(2)\end{array}$ & $\begin{array}{c}\text { Between } \\
\text { (3) }\end{array}$ & & & \\
\hline 1991 & -14.5 & -17.9 & 3.4 & -0.8 & 3.0 & -12.4 \\
\hline 1992 & -3.1 & -17.3 & 14.2 & -1.4 & 2.9 & -1.6 \\
\hline 1993 & -11.5 & -10.0 & -1.5 & -3.3 & 3.6 & -11.2 \\
\hline 1994 & -5.1 & 2.1 & -7.2 & -0.3 & 3.6 & -1.7 \\
\hline 1995 & -6.6 & -6.5 & -0.1 & -1.7 & 2.3 & -6.1 \\
\hline 1996 & -13.2 & -20.6 & 7.4 & -0.4 & 3.3 & -10.4 \\
\hline 1997 & -19.0 & -24.8 & 5.7 & -1.2 & 4.0 & -16.2 \\
\hline 1998 & -15.5 & -5.0 & -10.5 & -1.8 & 2.7 & -14.6 \\
\hline 1999 & -7.9 & -3.8 & -4.1 & -1.2 & 2.9 & -6.2 \\
\hline 2000 & -5.0 & -11.3 & 6.3 & -1.5 & 2.9 & -3.7 \\
\hline 2001 & -20.8 & -16.1 & -4.8 & 1.6 & 4.2 & -14.9 \\
\hline
\end{tabular}

Note: Percentage change in industry pollution emissions intensity attributable to surviving, entering and exiting establishments. Change in emissions in surviving establishments are further decomposed into changes within establishments in column 2, which we term a process effect, and reallocation among survivors in column 3.

to be towards dirtier establishments, driven primarily by the exit of relatively clean establishments. This is offset by the relentless cleanup in surviving establishments which drives the overall cleanup from plants in the analysis sample. The results based on this approach support the conclusion that the cleanup is not being driven by environmental regulation forcing old, pollution intensive manufacturing establishments out of business.

As is the case when entry and exit are defined at the firm level, exiting establishments tend, on average, to be cleaner than the incumbents they leave behind. As a result, selection continues to contribute to higher emissions with exit defined at the establishment level. The decline in the aggregate technique effect masks the fact that exit of relatively clean establishment appears to contribute a 2.3 to 4.2 percent increase in emissions, depending on the year--similar to the results estimated when exit is defined at the firm level. To better understand this result we aggregated the effect of exiting establishments on total emissions from our sample by industry and year. Industrial organic chemicals (SIC 2869) experiences the most exit from relatively clean establishments, but paper mills (SIC 2611) and pulp mills (SIC 2621) are not far behind. Using this approach, only a handful of manufacturing industries (29 out of 450 in our sample) get cleaner due to exit of relatively dirty establishments. Only for wet corn milling (SIC 2046) and household cooking equipment (SIC 3631) does exit of relatively dirty establishments contribute more than 0.1 percent to the overall clean up.

Comparing the results from the two alternative entry-exit definitions together the findings 
give some additional insight into the operations of manufacturing firms and their environmental consequences. In particular, our results indicate that a substantial portion of the aggregate technique effect is due to firms merging cleaner operations with dirtier (a within firm reallocation effect), and not merely from the installation or adjustment of production technologies at the dirtier establishments. 